\title{
OUTCOME OF ELECTIVE PROPHYLACTIC ILIOINGUINAL NEURECTOMY IN PREVENTION OF CHRONIC GROIN PAIN AFTER OPEN INGUINAL HERNIA REPAIR
}

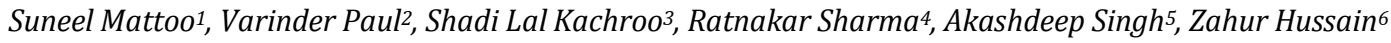 \\ ${ }^{1}$ Post Graduate, Department of General Surgery, Government Medical College, Jammu. \\ 2 Post Graduate, Department of General Surgery, Government Medical College, Jammu. \\ 3 Professor, Department of General Surgery, Government Medical College, Jammu. \\ ${ }^{4}$ Associate Professor, Department of General Surgery, Government Medical College, Jammu. \\ ${ }^{5}$ Registrar, Department of General Surgery, Government Medical College, Jammu. \\ ${ }^{6}$ Associate Professor, Department of General Surgery, Government Medical College, Jammu.
}

\begin{abstract}
\section{BACKGROUND}

Chronic groin pain is one of the most important complications of the repair of inguinal hernia. Randomized trials have identified that chronic groin pain $(>10 \%)$ surpasses recurrence $(<2 \%)$. Factors proposed as predictors of post-operative pain are damage to inguinal nerves, nerve entrapment during suturing, fibrosis of the placed material as well as that of surrounding area, mesh implantation, partial division and neuroma formation. Routine ilioinguinal division or excision has been associated with a lower incidence of post-operative neuralgia compared to nerve preservation with reduced morbidity and no detrimental effect on quality of life.
\end{abstract}

\section{OBJECTIVE}

The purpose of our study was to assess the effects of prophylactic ilioinguinal neurectomy on the incidence and intensity of groin pain after open inguinal hernia repair.

\section{PATIENTS AND METHODS}

A total of 50 patients with uncomplicated inguinal hernias were subjected to Lich tenstein mesh hernioplasty with prophylactic ilioinguinal neurectomy over a period of one year (November 2014 - October 2015). Relation of pain to Rest (R), Activities (A) and Exercise (E) preoperatively and at 1, 3 and 6 months after surgery was noted. McGill Pain Questionnaire was used to assess pain 1 week after surgery, 4 weeks after surgery and after 3 and 6 months of surgery.

\section{RESULTS}

Routine ilioinguinal neurectomy during open groin hernia repair was associated with mean McGill pain score of 1.76 and 1.48 at follow-up period of 3 and 6 months, respectively. Numbness was present in 12\% patients at follow-up period of 3 and 6 months. At 3 and 6 months follow-up, pain at rest was present in $2 \%$ and $0 \%$ patients; pain only during daily activities was present in $4 \%$ and $2 \%$ patients; and pain only during exercise was present in $6 \%$ and $4 \%$ patients, respectively. Only $2 \%$ patients required analgesics to control pain at 3 months and no patient required analgesics to control pain at 6 months.

\section{CONCLUSIONS}

Ilioinguinal neurectomy during open inguinal hernia repair is safe and effective procedure associated with low chronic pain scores and with no significant impairment in quality of life.

\section{KEYWORDS}

Ilioinguinal Neurectomy, Chronic Groin Pain, Inguinal Hernia.

HOW TO CITE THIS ARTICLE: Mattoo S, Paul V, Kachroo SL, et al. Outcome of elective prophylactic ilioinguinal neurectomy in prevention of chronic groin pain after open inguinal hernia repair. J. Evolution Med. Dent. Sci. 2016;5(35):1992-1997,

DOI: $10.14260 /$ jemds/2016/470

\section{INTRODUCTION}

Inguinal hernia is a common problem with a lifetime risk of $27 \%$ for men and $3 \%$ for women.(1) Chronic groin pain is one of the most important complications of the repair of inguinal hernia. Randomized trials have identified that chronic groin pain $(>10 \%)$ surpasses recurrence $(<2 \%)$ and is an important measure of success. $(2)$

Financial or Other, Competing Interest: None.

Submission 21-02-2016, Peer Review 23-03-2016,

Acceptance 28-03-2016, Published 30-04-2016.

Corresponding Author:

Dr. Suneel Mattoo,

158/3, Bhagwati Nagar Extension,

Jammu-180016,

J\&K, India.

E-mail: suneelmattoo@gmail.com

DOI: $10.14260 /$ jemds $/ 2016 / 470$
Its intensity can also potentially jeopardize patient's work and social activities and the treatment is often difficult and challenging.

The International Association for the Study of Pain (IASP) defines chronic pain as a pain lasting for greater than 3 months after the injury. Incidence of chronic groin pain influencing daily activities varies in literature, but based on general agreement may occur in $5-10 \%$ patient.(3)

Based on the classification of pain by the IASP, postherniorrhaphy inguinodynia can be broadly divided into nociceptive and neuropathic pain.

Nociceptive pain is caused by activation of nociceptive molecules due to tissue injury or inflammatory reaction, and transmitted to the brain via A-delta and C-fibers. Nociceptive pain can be reduced by gentle tissue handling using local anaesthesia to reduce production of nociceptive molecules and avoiding forceful tissue retraction. 
Neuropathic pain is caused by direct nerve injury and characterized by inguinodynia with radiation to scrotum/femoral triangle, paraesthesia, allodynia, hyperpathia, hyperalgesia, hypoesthesia and positive Tinel sign.

At present we are unable to clearly differentiate chronic neuropathic from nociceptive pain following groin hernia repair, although nerve damage seems to be a pre-requisite for development of chronic pain..$^{(4,5)}$

Factors proposed as predictors of post-operative pain are damage to inguinal nerves.(6), nerve entrapment during suturing.(7), fibrosis of the placed material as well as that of surrounding area, mesh implantation, partial division and neuroma formation. ${ }^{(8)}$

Inguinal nerves include the ilioinguinal nerve, the iliohypogastric nerve and the genital branch of the genitofemoral nerve. Elective division or resection of the ilioinguinal nerve has been proposed by many authors to reduce the risk of postoperative pain, which is one of the most significant complications after open inguinal hernia repair.

Routine ilioinguinal division or excision has been associated with a significantly lower incidence of postoperative neuralgia compared to routine nerve preservation with significantly reduced morbidity and no detrimental effect on quality of life and has been proposed by many studies as a routine surgical step. $(9,10,11,12,13,14,15,16,17)$

Despite the apparent paradox of higher tissue damage, resection of selected segments of inguinal nerves appears an effective technique in preventing chronic post-herniorrhaphy pain with lower incidence and faster resolution of painful symptomatology.(18)

But many studies have on the other hand suggested that identification and preservation of the inguinal nerves during the surgery is associated with better patient outcome in terms of pain. $(8,19,20,21,22,23,24)$

Further studies are thus required to address this issue. So, it was planned to study the effect of resection of ilioinguinal nerve after tension-free open inguinal hernia repair in prevention of chronic groin pain.

\section{AIMS AND OBJECTIVES}

- To assess the effects of prophylactic ilioinguinal neurectomy on the incidence and intensity of groin pain after open inguinal hernia repair.

\section{MATERIALS AND METHODS}

This study was carried out over a period of one year (November 2014 - October 2015) in 50 patients in Government Medical College Hospital, Jammu, which is a tertiary care hospital/referral centre and routinely receives patients with inguinal hernias. An approval from the Institutional Ethics Committee was taken prior to initiating the study.

All patients satisfying the following criteria were considered to be eligible for the study.

\section{Inclusion Criteria}

1. Both male and female patients.

2. Age more than 18 years.

3. Inguinal hernia of any duration and type.

\section{Exclusion Criteria}

1. Patients with recurrent hernia, femoral hernia, hydrocele and varicocele on the side of hernia.

2. Previous abdominal surgery.

3. Coexisting neurologic disease or any other disease that may cause local discomfort or pain.

4. Complicated hernias like irreducible, obstructed and/or strangulated.

5. Patients with other ailments taking medications commonly known to have neurosensory effects.

6. Those who fail to give written informed consent.

Lichtenstein's mesh hernioplasty with polypropylene mesh was performed in all patients. Only spinal anaesthesia was used. While lifting the cord, the ilioinguinal nerve was identified, the whole nerve was excised as far lateral to the deep ring as possible with the cut ends left alone without implantation into muscle or ligation.

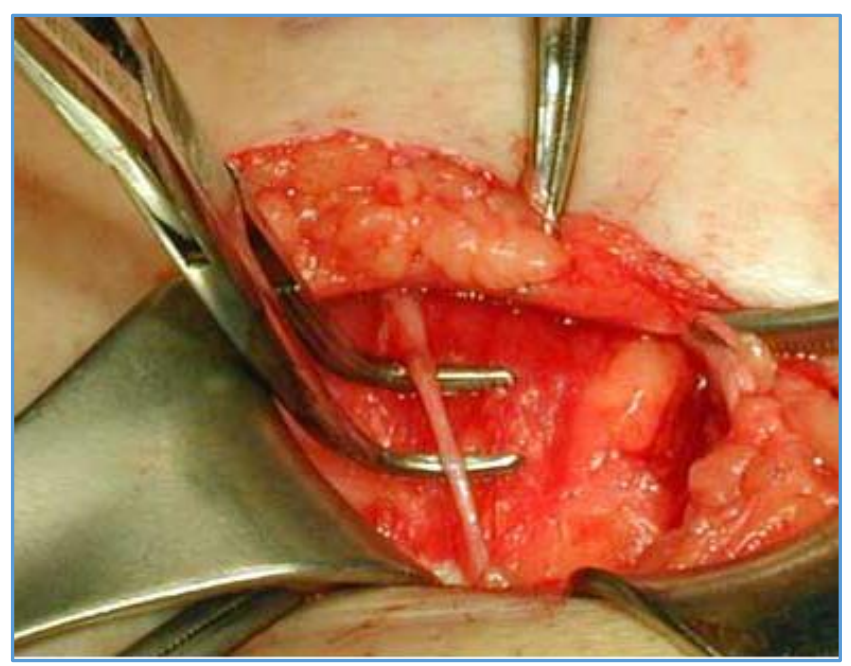

Fig. 1: Intraoperative Photograph of Ilioinguinal Nerve

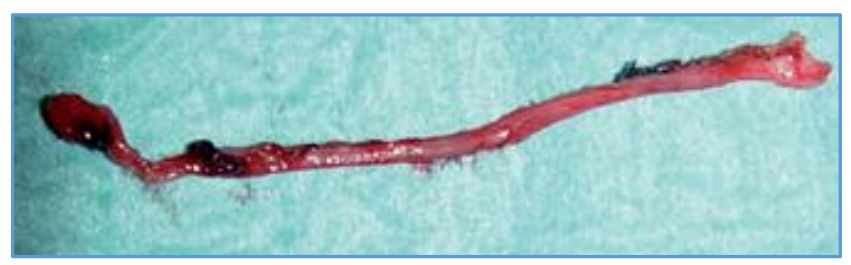

Fig. 2: Resected Segment of Ilioinguinal Nerve

McGill Pain Questionnaire was administered in all patients preoperatively, and after 1 week and 1, 3 and 6 months of surgery.

The complex nature of pain suggests that the diverse measurements considered may not always show high concordance. Because pain is subjective, the patient's selfreport provides the most valid measure of the experience, especially when concordance is low. The most frequently used self-rating instruments for pain measurement that assess the multidimensional nature of pain are the McGill Pain Questionnaire which has been shown to be reliable, valid and consistent measurement tool.

A standard form McGill Pain Questionnaire is a selfadministered measure that consists of 78 pain descriptors (words), distributed across 20 items, which are further 
classified into 4 subclasses: The sensory class includes 10 items. The affect class contains 5 items. The evaluative class includes 1 item and the miscellaneous class contains 4 items. The total class includes all of the items from 1 to 20 . Each word is assigned a rank value indicative of the relative intensity of pain. In this scale, pain intensity is based on an intensity scale from 1 to 5 .

The major measure of the McGill Pain Questionnaire is the pain rating index, which is obtained by adding the rank values of the words chosen for each category and the total score. The present pain intensity has a range of 1 (Mild) to 5 (Excruciating).

\section{OBSERVATIONS}

Age

In the present study, age ranged from 20-70 years. Mean age was 49.52 years with a standard deviation of 13.99 .

\section{Type of Hernia}

Majority of patients (76\%) had an indirect hernia. Rest had a direct $(18 \%)$ or a pantaloon $(6 \%)$ hernia.

\section{Side of Hernia}

$54 \%$ patients had hernia on the left side and $46 \%$ patients had hernia on the right side.

\section{Duration of Hernia}

In this study, patients had a hernia for duration of 0.5 to 10 years. Mean duration was 3.31 years, median duration of 3 years with a standard deviation of 2.09 years.

\section{Size of Hernia}

$76 \%$ patients had an incomplete hernia and only $28 \%$ patients had a complete hernia reaching the bottom of scrotum.

\section{Coexisting Conditions/Diseases}

Benign Hyperplasia of Prostate (BHP) was found in $18 \%$ patients, chronic constipation in $14 \%$ patients and Chronic Obstructive Pulmonary Disease (COPD) in 8\% patients. No other potential predisposing factor was found in rest of the patients.

\section{Distribution of Patients According to Pain, Numbness and Other Sensory Complaints}

Preoperatively, only $2 \%$ patients had pain at rest, $14 \%$ had pain during daily activities and $84 \%$ had pain only during exercise. Patients with numbness and other complaints like paraesthesias, etc. were not included in the study. The number of patients experiencing pain at all levels of activity was lesser at 1, 3 and 6 months postoperatively.

\begin{tabular}{|c|c|c|c|c|}
\hline Pain & Preoperatively & $\begin{array}{c}\text { At 1 } \\
\text { Month }\end{array}$ & $\begin{array}{c}\text { At 3 } \\
\text { Months }\end{array}$ & $\begin{array}{c}\text { At 6 } \\
\text { Months }\end{array}$ \\
\hline At rest (R) & 2 & 2 & 2 & 0 \\
\hline $\begin{array}{c}\text { Daily } \\
\text { Activities } \\
\text { (A) }\end{array}$ & 14 & 6 & 4 & 2 \\
\hline Exercise (E) & 84 & 10 & 6 & 4 \\
\hline $\begin{array}{c}\text { Numbness } \\
\text { (N) }\end{array}$ & 0 & 16 & 12 & 12 \\
\hline $\begin{array}{c}\text { Other } \\
\text { sensory } \\
\text { complaints } \\
\text { (S) }\end{array}$ & 0 & 20 & 16 & 16 \\
\hline $\begin{array}{c}\text { Table 1: Distribution of Patients According to Pain, Numbness } \\
\text { and Other Sensory Complaints No. of Patients (\% Age) }\end{array}$ \\
\hline
\end{tabular}

At 1, 3 and 6 months, pain at rest was present in 2, 2 and $0 \%$ patients; pain only during daily activities was present in 6 , 4 and $2 \%$ patients; and pain only during exercise was present in 10, 6 and 4\% patients, respectively as shown in Figure 3.

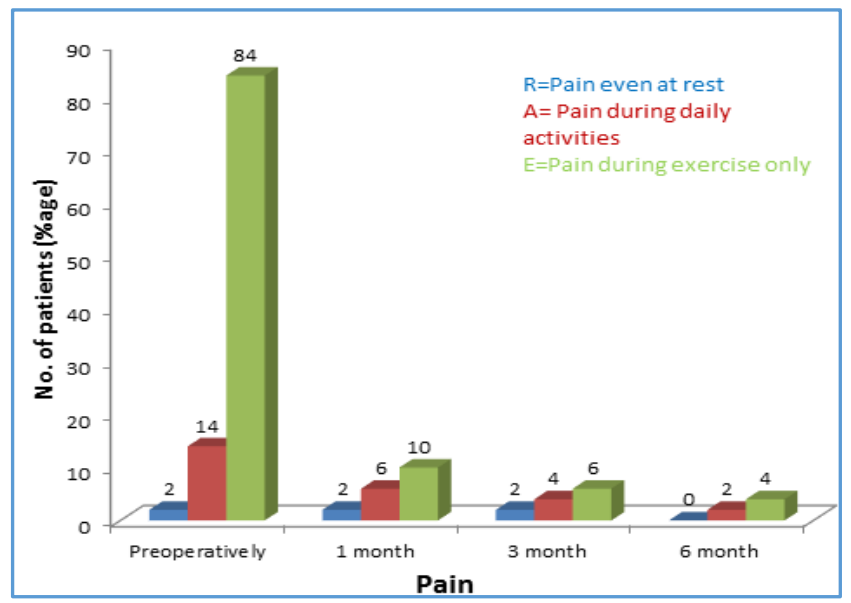

Fig. 3: Distribution of Patients According to Pain Preoperatively and at 1, 3 and 6 Months

At 1, 3 and 6 months, numbness was present in 16, 12 and $12 \%$ patients; and other sensory complaints like paraesthesias, etc. were present in 20, 16 and 16\% patients, respectively as shown in Figure 4.

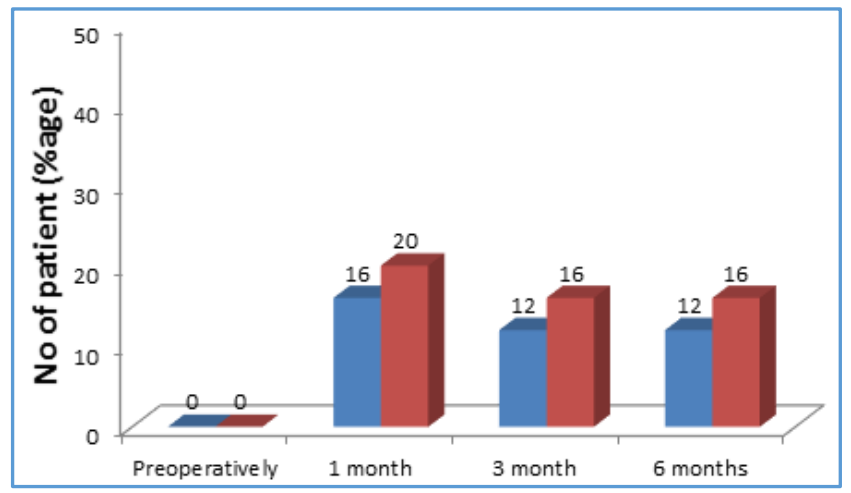

Fig. 4: Distribution of Patients According to Numbness and Other Sensory Complaints Preoperatively and at 1, 3 and 6 Months

\section{Postoperative Complications}

Postoperatively, urinary retention occurred in 36\% patients, haematoma/seroma was noted in 105 patients and wound infection occurred in $8 \%$ patients.

\section{McGill Pain Score}

Mean Total Pain Score (T) on McGill Pain Questionnaire was $2.44,7.58,3.26,1.76$ and 1.48 respectively preoperatively and at 1 week, 1 month, 3 months and 6 months. Corresponding mean Present Pain Intensity (PPI) was 1.12, 1.12, 1.14, 0.54 and 0.4 , respectively. 


\begin{tabular}{|c|c|c|c|c|c|c|}
\hline \multirow{2}{*}{ Time } & \multicolumn{3}{|c|}{$\begin{array}{c}\text { Total Pain } \\
\text { Score (T) }\end{array}$} & \multicolumn{3}{c|}{$\begin{array}{c}\text { Present Pain } \\
\text { Intensity (PPI) }\end{array}$} \\
\hline & Min & Max & Mean \pm S.D & Min & Max & Mean \pm S.D \\
\hline z & 1 & 7 & $2.44 \pm 1.92$ & 1 & 2 & $1.12 \pm 0.33$ \\
\hline At 1 week & 3 & 17 & $7.58 \pm 3.23$ & 1 & 2 & $1.12 \pm 0.33$ \\
\hline At 1 month & 1 & 11 & $3.26 \pm 2.63$ & 1 & 3 & $1.14 \pm 0.40$ \\
\hline At 3 months & 0 & 9 & $1.76 \pm 2.50$ & 0 & 3 & $0.54 \pm 0.79$ \\
\hline At 6 months & 0 & 9 & \multicolumn{7}{|c|}{$1.48 \pm 2.43$} & 0 & 3 & $0.4 \pm 0.70$ \\
\hline
\end{tabular}

\begin{tabular}{|c|c|c|c|c|c|}
\hline Scale and Subscale & Pre-operatively & 1 Week & 1 Month & 3 Month & 6 Month \\
\hline Sensorial & $0.76(1.22)$ & $6.54(2.11)$ & $2.58(1.74)$ & $1.08(1.55)$ & $0.88(1.44)$ \\
\hline Affective & $0.36(8.60)$ & $0.44(0.79)$ & $0.36(0.66)$ & $0.32(0.55)$ & $0.28(0.57)$ \\
\hline Evaluative & $1.16(0.37)$ & $0.56(0.73)$ & $0.18(0.44)$ & $0.16(0.37)$ & $0.16(0.42)$ \\
\hline Miscellaneous & $0.16(0.37)$ & $0.04(0.20)$ & $0.14(0.40)$ & $0.2(0.53)$ & $0.18(0.44)$ \\
\hline PRI & $2.24(1.92)$ & $7.58(3.30)$ & $3.26(2.63)$ & $1.76(2.50)$ & $1.48(2.43)$ \\
\hline PPI & \multicolumn{1}{|c|}{$1.12(0.33)$} & $1.12(0.33)$ & $1.14(0.40)$ & $0.54(0.79)$ & $0.4(0.70)$ \\
\hline
\end{tabular}

Values in parentheses represent standard deviation.

\section{Need of Analgesics to Control Pain}

At 1 week, $16 \%$ patients required analgesics to control pain. At 1,3 and 6 months, $4 \%, 2 \%$ and $0 \%$ patients required the analgesics to control pain, respectively.

\section{DISCUSSION}

Inguinal hernia is a common problem. This study revealed that most (48\%) of the cases of inguinal hernia were between 30 50 years of age group with mean age of 49.52 years, as previously observed by Haq et al.(25) Contrary to this, Sanjay and Woodward noticed predominantly younger age group in their case series of 153 inguinal hernia patients.(26) Thus, inguinal hernia is a disease of all age groups. Prolonged straining and heavy lifting are mostly the causes in younger patients, while urinary problems are chief aetiology in older ages as a result of benign prostatic hyperplasia.

Inguinal hernia is more frequent in males. Paajanen and Varjo observed $97 \%$ of males and $3 \%$ of females in their tenyear audit of Lichtenstein repair of 281 patients.(27) Alfieri et al also encountered major proportion of male patients in their prospective case study. We encountered $100 \%$ male patients in this study. ${ }^{(8)}$

Chronic groin pain is a significant complication after open inguinal hernia repair, which can significantly affect patient satisfaction and quality of life. Normal postoperative pain affects patients immediately after surgery and gradually subsides within a few days. Some patients experience chronic debilitating pain that is often unresponsive to medical treatment including non-steroidal anti-inflammatory drugs and opiates. The exact cause of this pain is unknown. One of the mechanisms responsible for this chronic pain may be the damage to the ilioinguinal nerve passing through the inguinal region. It may be traumatized during surgery and/or entrapped in scar tissue or mesh.

Residual pain should be viewed as an essential endpoint when assessing the outcome of hernia surgery. After 24 to 36 months, nearly $30 \%$ of the patients reported some form of pain or discomfort and close to $6 \%$ of all patients reported inguinal pain of such intensity that it disturbed their concentration in activities of daily life during the week preceding follow-up.(28) The report from the Danish Hernia Data Base Group suggests that the incidence of chronic pain regardless of grade, 12 months after surgery, is approximately $29 \%$ with $11 \%$ of patients complaining of severe pain.(8) In a study, the rates of chronic pain after 6 months and 5 years were $16.5 \%$ and $16.1 \%$, respectively. ${ }^{(29)}$

Ravichandran D et al evaluated the differences in the incidence of pain between the ilioinguinal nerve 'preserved' and 'divided' sides and did not find any significant difference in the pain between both sides. He found that at 6 months postoperatively, pain was present in $5 \%$ patients on the nerve preserved side versus $0 \%$ on the nerve division side.(9) In another randomized controlled trial, there was a lower incidence of chronic pain in the neurectomy group compared to the non-neurectomy group at 6 months.(12) Malekpour et al found that post-operational pain was less in nerve-excised group in the first month after surgery. But 6 months and 1 year post-surgery, no significant differences were found.(13)

The potential disadvantage of nerve excision reported in literature is the morbidity associated with sensory loss over the groin region. Although Picchio and Associates reported an increased incidence of sensory loss to pain and touch around the groin region. $(20)$, others announced that no significant differences were found regarding the incidence of groin numbness and sensory loss or changes in patients who had nerve excision during open hernia repair.(9,12) Tsakayannis and associates also reported the incidence of numbness as 
$6.28 \%$ and sensory loss as $1.04 \% 1$ year after surgery in patients who had ilioinguinal and iliohypogastric nerve excision during hernia repair.(11)

In study by Karakayali $\mathrm{F}$ et al in the ilioinguinal neurectomy group at one month follow-up, pain was present in $21 \%$ patients with pain at rest in $8 \%$ and pain with daily activities in $7 \%$ patients. Groin numbness was present in $11 \%$ patients and other sensory changes in 31\% patients.(14) In our study at one month postoperatively, pain was present in $10 \%$ patients with pain at rest in only $2 \%$ and pain with daily activities in $6 \%$ patients. Groin numbness was present in $16 \%$ patients and other sensory changes in $20 \%$ patients.

At one year follow-up, Karakayali et al found that pain was present in $7 \%$ patients with no patient reporting pain at restand only $3 \%$ patients reporting pain on daily activities and rest reporting pain only on exercise.(14) Groin numbness was present in $4 \%$ and sensory loss in $14 \%$ patients. One of the limitations of our study was that follow-up period was only 6 months. At six months follow-up, we found that the pain was present in $4 \%$ patients only with no patient reporting pain at rest, $2 \%$ reporting pain on daily activities and rest only on exercise. Groin numbness in our study was present in $12 \%$ patients and sensory loss in $16 \%$ patients at 6 months.

Mean Pain Rating Index on McGill Pain Questionnaire was found to be 3.1 (S.D=4.3) and 0.8 (S.D=2.1) respectively at one month and one year in Karakayali et al (2010) study. The index at one month and six months in our study was found to be 3.26 (S.D=2.63) and 1.48 (S.D=2.43).

Another important aspect of neurectomies is the impact of residual pain or sensory changes on the quality of life. Karakayali et al observed high incidences of groin numbness and sensory loss or change in the neurectomies group, but no statistically significant differences were noted among the groups regarding preoperative and 1 year follow-up in terms of patient's quality of life.(14) In none of our patients, quality of life was compromised much as no patient had rest pain at 6 months, $2 \%$ and $4 \%$ patients reported pain only on daily activities and exercise, respectively at 6 months. Though numbness was present in $16 \%$ patients, but it was not significant enough to lead to a limitation in daily activities. Only $2 \%$ patients required analgesics at 3 months and no patient required analgesic at 6 months.

We performed wide resection of the ilioinguinal nerve. Zannoni $\mathrm{M}$ et al found that the prophylactic wide resection of selected segments of inguinal nerves, despite the apparent paradox of greater tissue damage appeared more effective than simple section at preventing postoperative inguinodynia, given both the lower incidence and the faster resolution of painful symptomatology.(30) The degree to which this technical step contributes to prevent postoperative neuralgias remains unanswered in our study. Randomized controlled trials are required for this purpose.

In the literature a highly variable incidence of chronic pain exists, ranging to well above $10 \%$ in some series. $(2,28,31)$ The number of subjects in our study was only 50 , which limits its use for projection at a larger scale. Therefore, prospective, multicentre studies that include more patients should be done to determine how to prevent chronic groin pain. Another probable reason of such variability is the subjectivity of the pain experience. The validity of the data that assess a highly subjective factor such as neuropathic pain depends on the methods used for pain assessment. We used the McGill Pain Questionnaire to assess the multidimensional nature of the pain experience, which contains 78 pain descriptors including neuropathic pain descriptors (sharp, shooting, pricking or burning). Data on the severity of pain, based on patient's selfreports are especially exposed to bias owing to inter-patient variation in the perception of pain. This is another potential limitation of our study.

Another controversy that has arisen in recent years is regarding the role of multiple neurectomies. Karakayali et al found no statistically significant difference regarding chronic groin pain between ilioinguinal and iliohypogastric nerve excision during open hernia repair.(14) This issue has not been addressed in this study.

Despite the limitations mentioned above, this study at least establishes that ilioinguinal neurectomy during open inguinal hernia repair is a safe procedure with no significant morbidity or impact on quality of life and will be able to serve as a benchmark for future studies in this area.

\section{REFERENCES}

1. Jenkins JT, O'Dwyer PJ. Inguinal hernias. BMJ 2008;336(7638):269-72.

2. Simons MP, Aufenacker T, Bay-Nielsen M, et al. European hernia society guidelines on the treatment of inguinal hernia in adult patients. Hernia 2009;13(4):343-403.

3. Kehlet $\mathrm{H}$. Chronic pain after groin hernia repair. Br J Surg 2008;95(2):135-6.

4. Haapaniemi S, Nilsson E. Recurrence and pain three years after groin hernia repair validation of postal questionnaire and selective physical examination as a method of follow-up. Eur J Surg 2002;168(1):22-8.

5. Kehlet H, Jensen TS, Woolf CJ. Persistent postsurgical pain: risk factors and prevention. Lancet 2006;367(9522):1618-25.

6. Bower S, Moore BB, Weiss SM. Neuralgia after inguinal hernia repair. Am Surg 1996;62(8):664-7.

7. Madura JA, Madura JA, Copper $\mathrm{CM}$, et al. Inguinal neurectomy for inguinal nerve entrapment: an experience with 100 patients. Am J Surg 2005;189(3):283-7.

8. Alfieri S, Rotondi F, Di Giorgio A, et al. Influence of preservation versus division of ilioinguinal, iliohypogastric, and genital nerves during open mesh herniorrhaphy: prospective multicentric study of chronic pain. Ann Surg 2006;243(4):553-8.

9. Ravichandran D, Kalambe BG, Pain JA. Pilot randomized controlled study of preservation or division of ilioinguinal nerve in open mesh repair of inguinal hernia. Br J Surg 2000;87(9):1166-7.

10. Dittrick GW, Ridl K, Kuhn JA, et al. Routine ilioinguinalnerveexcision in inguinal hernia repairs. Am J Surg 2004;188(6):736-40.

11. Tsakayannis DE, Kiriakopoulos AC, Linos DA. Elective neurectomy during open, "tension free" inguinal hernia repair. Hernia 2004;8(1):67-9.

12. Mui WL, Ng CS, Fung TM, et al. Prophylactic ilioinguinalneurectomy in open inguinal hernia repair: a double-blind randomized controlled trial. Ann Surg 2006;244(1):27-33. 
13. Malekpour F, Mirhashemi SH, Hajinasrolah E, et al. Ilioinguinalnerveexcision in open mesh repair of inguinal hernia-results of a randomized clinical trial: simple solution for a difficult problem? Am J Surg 2008;195(6):735-40.

14. Karakayali F, Oksuz E, Turk E, et al. Effectiveness of multiple neurectomies to prevent chronic groin pain after tension-free hernia repair. Int Surg 2010;95(1):408.

15. Crea N, Pata G. Effects of prophylactic ilioinguinal nerve excision in mesh groin hernia repair: short- and longterm follow-up of a randomized clinical trial. Am Surg 2010;76(11):1275-81.

16. Johner A, Faulds J, Wiseman SM. Planned ilioinguinalnerveexcision for prevention of chronic pain after inguinal hernia repair: a meta-analysis. Surgery 2011;150(3):534-41.

17. Khoshmohabat H, Panahi F, Alvandi AA, et al. Effect of ilioinguinalneurectomy on chronic pain following herniorrhaphy. Trauma Mon 2012;17(3):323-8.

18. Zannoni M, Luzietti E, Viani L, et al. Wide resection of inguinal nerves versus simple section to prevent postoperative pain after prosthetic inguinal hernioplasty: our experience. World J Surg 2014;38(5):1037-43.

19. Izard G, Gailleton R, Randrianasolo S, et al. Treatment of inguinal hernia by McVay's technique apropos of 1332 cases. Ann Chir 1996;50(9):755-66.

20. Picchio M, Palimento D, Attanasio U, et al. Randomized controlled trial of preservation or electivedivision of ilioinguinalnerve on openinguinal herniarepair with polypropylenemesh. Arch Surg 2004;139(7):755-8. discussion 759.

21. Wijsmuller AR, Van Veen RN, Bosch JL, et al. Nerve management during open hernia repair. Br J Surg 2007;94(1):17-22.
22. Amid PK, Hiatt JR. New understanding of the causes and surgical treatment of postherniorrhaphyinguinodynia and orchalgia. J Am Coll Surg 2007;205(2):381-5.

23. Bartlett DC, Porter C, Kingsnorth AN. A pragmatic approach to cutaneous nervedivision during open inguinal hernia repair. Hernia 2007;11(3):243-6.

24. Smeds S, Löfström L, Eriksson 0 . Influence of nerveidentification and the resection of nerves 'at risk' on postoperative pain in open inguinal hernia repair. Hernia 2010;14(3):265-70.

25. Haq RN, Chaudhry IA, Khan BA, et al. Groin sepsis following lichtenstein inguinal hernioplasty without antibiotic prophylaxis: areview of 100 cases. Pak J Med Sci 2006;22(4):416-9.

26. Sanjay $P$, Woodward A. Inguinal hernia repair: local or general anaesthesia? Ann $\mathrm{R}$ Coll Surg Engl 2007;89(5):497-503.

27. Paajanen H, Varjo R. Ten-year audit of Lichtenstein hernioplasty under local anaesthesia performed by surgical residents. BMC Surg 2010;10:24.

28. Franneby U, Sandblom G, Nordin P, et al. Risk factors for long-term pain after hernia surgery. Ann Surg 2006;244(2):212-9.

29. Reinpold WM, Nehls J, Eggert A. Nerve management and chronic pain after open inguinal hernia repair: a prospective two phase study. Ann Surg 2011;254(1):163-8.

30. Zannoni M, Nisi P, Laria M, et al. Wide nervous section to prevent post-operative inguinodynia after prosthetic hernia repair: a single center experience. Hernia 2015;19(4):565-70.

31. Rosenberg J, Bisgaard T, Kehlet H, et al. Danish hernia database recommendations for the management of inguinal and femoral hernia in adults. Dan Med Bull 2011;58(2):C4243. 